NBSIR 75.704 (R)

\title{
Investigation of a 1-Ton Tank-Car \\ Tank That Leaked Phosgene in \\ Easton, Pennsylvania on April 24, 1973
}

C. G. Interrante

Mechanical Properties Section

Metallurgy Division

Institute for Materials Research

National Bureau of Standards

Washington, D. C. 20234

April 1975

Failure Analysis Report

Prepared for

Federal Railroad Administration

Department of Transportation

Washington, D. C. 20590 


\section{INVESTIGATION OF A 1-TON TANK-CAR \\ TANK THAT LEAKED PHOSGENE IN \\ EASTON, PENNSYLVANIA ON APRIL 24, 1973}

C. G. Interrante

Mechanical Properties Section

Metallurgy Division

Institute for Materials Research

National Bureau of Standards

Washington, D. C. 20234

April 1975

Failure Analysis Report

"This document has been prepared for the use of the Federal Railroad Administration, Department of Transportation, Washington, D.C. Responsibility for its further use rests with that agency. NBS requests that if release to the public is contemplated, such action be taken only after consultation with the Office of Public Affairs at the National Bureau of Standards."

\section{Prepared for}

Federal Railroad Administration

Department of Transportation

Washington, D. C. 20590

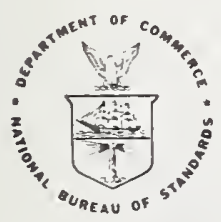

\section{U.S. DEPARTMENT OF COMMERCE, Rogers C.B. Morton, Secretan}





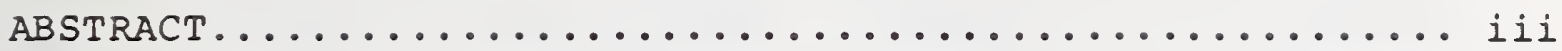

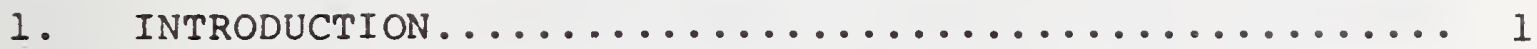

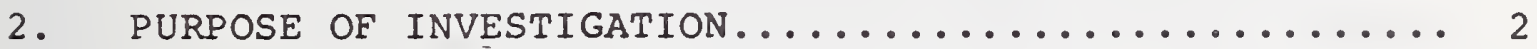

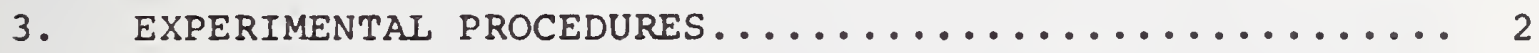

4. RESULTS AND DISCUSSIONS................... 4

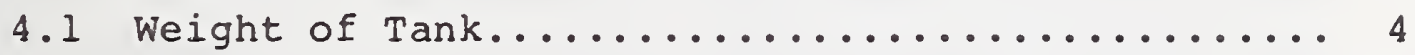

4.2 Examinations for Cracks................ 4

4.3 Visual Examinations................... 4

4.4 Metallographic Examinations.............. 5

4.5 Scanning-Electron-Microscope Examinations...... 8

5. SUMmaRY ON THE NATURE AND CAUSE OF THE LEAK........ 9

6. ACKNOWLEDGEMENTS............................ 10

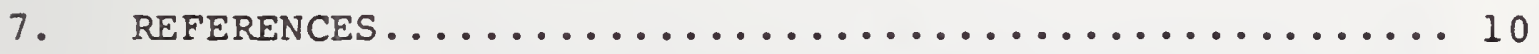

List of Figures

1. The tank after flame cutting to remove the end that leaked and the section that contained the leak.

2. The section that contained the leak, as flame-cut from the tank.

3. Eight 1-inch segments as saw-cut from the section that contained the leak.

4. Eight 1-inch segments in the rough-ground condition.

5. Eight 1 -inch segments from near the leak and two end segments taken from the section that contained the leak, in the cropped, polished, and etched condition. 


\section{List of Figures (continued)}

6. Inside of tank after removal of the end that leaked.

7. Montage of bond region on segment number 2 , face 1 .

8. Montage of bond region on segment number 4 , face 1 .

9. Montage of bond region on segment number 5, face 1 .

10. Segment number 5 after being wedged open to examine for cracks, showing the location of a dark region (at the arrow) which represents a possible preexisting path through the tac weld.

11. Two sections taken in the weld metal on the headplate portion of fractured segment 5, showing surface (IIA) and sub-surface (IIB) defects and oxides that surround them.

12. SEM fractograph of fracture face of segment 5 taken at $\mathrm{X} 5$ magnification.

13. SEM fractographs taken at X48 (Fig. 13A.) and X240 (Fig. 14B.) showing microporosity in the dull region and crystalline fracture in the adjacent parts of the fracture.

14. SEM fractographs of the dull region (Figure 14A), showing microporosity and dimpled rupture, and of a region representative of the balance of the fracture (Figure 14B), showing a crystalline appearance. 


\section{ABSTRACT}

At the request of the Standards and Procedures Division, Federal Railroad Administration, Department of Transportation, an investigation was conducted at the National Bureau of Standards (NBS) on a l-ton tank-car tank, which reportedly failed in service by leaking phosgene gas in Easton, Pennsylvania. The tank was shipped to NBS where it was sectioned and examined to determine the nature and possible cause of the leak.

No gross defects, through which phosgene gas could have leaked, were observed and it is believed that the leak occurred through a path of very small size, which probably existed either along the fusion boundary of or within the weld metal of a tac weld present in the region of the leak. The forged weld present at locations remote from the leak did not exist in the region of the leak and the available evidence indicates that this unbonded metal is the result of corrosion promoted by capillary action at the root of this weldment. It is believed that the observed leak was principally the result of corrosion from the inside of the vessel, and it is speculated that the failure of the vessel may have been accelerated by hydrotesting of the vessel and/or by service-related fatigue loads on the weld joint. 

Investigation of a 1-Ton Tank-Car Tank That Leaked Phosgene in Easton, Pennsylvania on April 24, 1973

\section{INTRODUCTION *}

A 1-ton tank-car tank failed at Richards Yard in Easton, Pennsylvania in April 24, 1973, by leaking while being used to transport Phosgene, a class A poisonous gas. When this leak was discovered, it was peened shut with a peening hammer. However, the escape of the gas resulted in the hospitalization of three railroad employees at Easton, Pennsylvania. Accordingly, the Federal Railway Administration requested that the National Bureau of standards conduct an inspection and failure analysis of this failed tank.

The tank was identified as CWS-A-5119, Lot P-479-1, tested 1/43, American Welding Company, Carbondale, Pennsylvania. Certificates furnished by the Association of American Railroads indicated that, for the vessel in question, the files of Robert W. Hunt Company, Engineers, Chicago, Illinois, show that: (1) the tank had been fabricated by a process that lapwelded the heads to the shell by water-gas forging; (2) the heat numbers for the heads, plates, and bottoms are 59C669,68C743, 62C730, respectively: (3) the January, 1943 tare weight and water capacity were 1590 pounds and 1680 pounds respectively; and (4) the mechanical properties of these steels were as follows:

\begin{tabular}{|c|c|c|c|c|c|}
\hline $\begin{array}{l}\text { Heat } \\
\text { No. } \\
\end{array}$ & $\begin{array}{l}\text { Yield } \\
\text { Point } \\
\text { (psi) } \\
\end{array}$ & $\begin{array}{l}\text { Tensile } \\
\text { Strength } \\
\text { (psi) } \\
\end{array}$ & $\begin{array}{l}\text { Elongation } \\
\text { (percent) }\end{array}$ & $\begin{array}{c}\text { Reduction } \\
\text { of Area } \\
\text { (percent) } \\
\end{array}$ & Test \\
\hline $59 C 669$ & 34,700 & 50,400 & 33.0 & 63.2 & Satisfactory \\
\hline $62 C 730$ & 31,100 & 51,100 & 34.0 & 67.7 & Satisfactory \\
\hline $68 C 743$ & 32,200 & 49,200 & 37.0 & 67.8 & Satisfactory \\
\hline
\end{tabular}

In addition, these files give the following chemical compositions (percent by weight, ladle analyses) for these heats of steels:

The material in this Introduction was provided by Mr. Quentin Banks, FRA. 
Heat No. C P

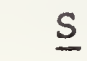

$\underline{\mathrm{Mn}}$

$59 C 669$

.12

.008

.026

.42

$62 C 730$

.11

.016

.034

.45

$68 C 743$

.12

.009

.030

.45

The tank was reported to have been hydrotested at 500 pounds pressure on each of the following dates: 1/43, $7 / 60,2 / 68$, and $3 / 73$. The leak in the tank was discovered in April of 1973, during the first service after the hydrotest of March 1973. During this service, the tank-car tank was reported to have been positioned near the rear of a railroad car that carried 15 of these 1-ton tanks.

\section{PURPOSE OF INVESTIGATION}

The purpose of this investigation is to determine the nature and possible cause of the leak in the forged weld seam of this tank-car tank.

\section{EXPERIMENTAL PROCEDURES}

The tank was weighed. Then it was inspected for cracks in the region of the leak by four methods: visual examination, magnetic-particle testing, dye-penetrant testing, and metallographic inspection of various sections of the forged weld seam in the vicinity of the leak. In addition, a section containing a one-inch $(2.5 \mathrm{~cm})$ length of the weld seam in the vicinity of the leak was fractured and examined for a pre-existing corrosion path from the inside to the outside of the vessel. The inside of the tank was visually examined.

The visual examinations were done by examining both the reported region of the leak and the interior of the tank by eye and with the aid of a hand magnifying lens. The magnetic-particle test procedure involved the use of iron oxide powder. When current is passed through the piece being tested the powder is selectively attracted to discontinuities at or very near the surface on which the powder is placed. The localization of the powder, as detected by eye, is taken as evidence of the location of a discontinuity at or very near the surface. The dye-penetrant test involved the use of red dye that penetrates by capillary attraction into any flaw or discontinuity present on the surface being tested. A white spray paint is placed onto the test surface and the dye present, inside of flaws in the surface, stains the 
white paint and this stain is taken as evidence of the presence of a flaw in the surface.

Before these inspections were made, paint was removed from the end of the tank in the region of the leak and this region was degreased to provide a clean surface for inspection. When these inspections were completed, the end of the tank that contained the leak was removed from the tank by a circumferencial torch cut at a distance of about

$91 / 2$ inches $(24 \mathrm{~cm})$ from the end that leaked in service, as shown in Figure 1 . The section that contained the leak was removed by another torch cut. This section is the piece that is missing in Figure 1 , and it is shown as Figure 2. Two arrows are seen in the figure. These were placed to point to two paint marks on the end of the tank. The paint marks were present on the tank when it was received at NBS, and they had been placed about 5 inches $(13 \mathrm{~cm}$ ) apart to bracket the location of the leak.

The region between the arrows was then saw cut from the balance of this torch-cut tank segment. Saw cuts were made at distances of about 1 l/2 inches $(4 \mathrm{~cm})$ beyond either end of the length between the two arrows. This saw-cut tank segment was about 8 inches $(20 \mathrm{~cm})$ in length, as measured along the circumference. This segment was further saw cut into eight approximately equal segments, which were numbered 1 through 8 , and they are shown in Figure 3 along with the part of the shell plate that adjoined these eight segments in the original $91 / 2$-inch $(24 \mathrm{~cm})$ long flame-cut section. These eight segments were then rough ground on a 60 grit paper wheel. The rough-ground segments are shown as Figure 4. The surfaces shown here are on the right sides of the segments as viewed on Figure 3, and this surface for each segment will be referred to as face 1 in the text to follow: face 2 is the other side of each of these segments.

Face 1 of each of these eight segments was prepared for metallographic examination by cropping at a distance of about $11 / 2$ inches $(3$ to $4 \mathrm{~cm}$ ) from the edge of the head-to-shell forged weld, and two additional sections were then prepared from the original flame-cut segment of Figure 2. The locations of these two sections are marked $1 B$ and $8 B$ in Figure 2, and $1 \mathrm{~B}$ face 1 and $8 \mathrm{~B}$ face 2 are shown in Figure 5 along with the other eight segments", in the polished-andetched condition in Figure 5.

* Only the shell piece of segment number 5 is shown in this figure. 
The surfaces shown in Figure 5 were carefully examined in various conditions of preparation, with the aim of detecting a continuous path from the interior to the exterior of the tank. To this end, these samples were also examined on other surfaces in other cross-sectional planes within these segments, so as to make possible (through photographic records) the tracing of voids through various planes within a segment. In addition, segment 5 was pulled apart completely severing the bond of a tac weld between the head and the shell pieces; the fracture surface attached to the shell was carefully examined by scanning electron microscopy and the weld metal on the fractured head piece was successively polished and examined at various depths below the fracture surface.

\section{RESULTS AND DISCUSSIONS}

\subsection{Weight of Tank}

The weight of the tank, as measured at NBS, was 1670 pounds $(752 \mathrm{~kg})$ plus 37 pounds $(17 \mathrm{~kg})$ for 10 bolts and 1 dome; for a total weight of 1710 pounds $(770 \mathrm{~kg})$. This contrasts with the 1590 pounds $(716 \mathrm{~kg})$ tare weight measured in 1943. The 10 bolts weighed $1-3 / 4$ pounds $(0.8 \mathrm{~kg})$ and the dome weighed $351 / 4$ pounds $(16 \mathrm{~kg})$.

\subsection{Examinations for Cracks}

The magnetic-particle and dye-penetrant inspections for cracks proved negative, and it was concluded that the peening of the end of the tank to stop the leak also effectively closed any surface flaws that were present.

\subsection{Visual Examinations}

Visual examination of the external parts of the tank revealed that the exact location of the leak on the end of the tank was not readily discernable. Between the two marks that had been placed on the end of the tank to locate the leak, there was a region of about 2 inches $(5 \mathrm{~cm})$ in length from which the paint on the surface of the tank had been removed. It was presumed that the peening hammers used to close off the leak had chipped this paint loose. This peened region is contained mainly in segments 4 and 5 , and so it was tentatively concluded that the tank had leaked in segments 4 and 5 .

Midway between segments 4 and 5 inside the tank, a corrosion line was observed. This line can be seen in Figure 3 on the plate in front of these segments, and it can be seen in Figure 6 , which shows the inside of the 
remainder of the tank after removal of the end that leaked. In Figure 6, this line is marked by an arrow. The line is bounded by two circles-one is the flame-cut shell plate and one is the head plate at the far end of the vessel--and the line is approximately midway between the 10 and the 11 o'clock positions on the circles.

Several cycles of corrosion are apparent in Figure 6 on the inside of the tank. Each cycle is believed to represent corrosion that occurred while the tank was partially filled while being stored flat along the long axis of the tank, and it appears that with each cycle, corrosion products were formed over a segment of the inside surfaces of a partially filled cylinder. Thus, at a previous boundary between the filled and unfilled parts, there exists a line, which is visible evidence of a difference in the corrosion experiences of the metal on the two sides of the line.

Both the rough-ground segments of Figure 4 and the polished segments of Figure 5 show that the bonded region extends for less than 0.4 inches $(1.0 \mathrm{~cm})$, in segments numbered 1 through 7 , and for about 0.6 inches $(1.5 \mathrm{~cm})$, in segment number 8 . The shortness of these lengths of the bond line are somewhat surprising, especially for segments 2,4 , and 5 which have bond line lengths of less than 0.2 inches $(0.5 \mathrm{~cm})$.

In the polished and etched condition (Figure 5), segments numbered 2,4 , and 5 were observed to have no fusion from lap welding, i.e. no forged weld region. The bonded metal shown here for these three segments is that of a tac weld at the end of the vessel. The other segments examined had at least some small length of forged weld metal along their bond lines. Segments $1 B$ and $8 B$ were taken from the ends of the original flame-cut section at distances somewhat remote from the leak, as marked on the photograph of Figure 2. In Figure 5, the polished and etched faces of these two segments clearly show forged weld metal in lengths of 1.3 inches $(3.3 \mathrm{~cm})$ for $8 B$ and 0.6 inches $(1.5 \mathrm{~cm})$ for $1 \mathrm{~B}$. Segment $8 \mathrm{~B}$ is more distant from the tac weld than any of the other segments examined, and $8 \mathrm{~B}$ has the longest forged weld region.

\subsection{Metallographic Examinations}

The as-polished-and-etched surfaces of the various segments were metallographically examined in detail, and these examinations revealed that the tac weld was present in 
sections 1 through 7 inclusive and it was not present in 1B, 8, and 8B. Special attention was focused on segments 4 and 5 in the attempts to determine the location of a continuous (micro) path for the escape of gas from the inside of the tank, but none of these attempts conclusively demonstrated that such a path existed.

A montage of photomicrographs was taken on face 1 of segments 2,4 , and 5 , each of which were bonded only by a tac weld with no lap weld being present. These montages are presented, respectively as Figure 7, 8, and 9. They show that the unbonded region extends (from inside the tank) to the root of the tac weld of segment 4 face 1 , and that the unbonded region extends beyond the root of the weld for a short distance along the fusion line of the tac weld in the other two segments. They also show, in the corroded forged weld regions near the tip of the unbonded part, that somewhat enlarged cavities have formed, presumably by corrosion that occurred in these regions at a rate greater than the rate at which it occurred at other nearby locations. These local regions, such as is shown near the tip of the crack of Figure 7, have a geometry that restricts the access to the bulk of the interior space of the tank. The formation of cavities such as those shown in Figure 7 is not unlike that observed in crevice corrosion. 1,2$)$ It is well known that mild steels are susceptible to crevice corrosion? )

In the tac weld, the fusion line between the weld metal and the base metal (head or shell) appears as a line defect and it seemed that a continuous path of voids might exist along one of these fusion boundaries. Careful metallographic examinations of the various segments showed that these fusion lines contained strings of intermittant inclusions, which apparently became localized and aligned at the fusion line as a result of the tac-welding operation.

These inclusions and the inclusions within the weld metal, as well as other defects present in the base metal in the vicinity of the weld metal were observed and photographed on various surfaces within the 10 segments. Successive planes of the selected segments were ground, polished, examined, etched, and reexamined in the search for a continuous path of voids from the inside to the outside of the tank.

The intersection of segments 4 and 5 was considered to be the most likely region for the leak, and attention was 
focused on finding a continuous path nearby segment 4 face 1 and segment 5 face 2. On segment 4 face 1 , eight successive planes were prepared and photographed at various depths up to 0.121 inches $(.31 \mathrm{~cm})$ from the original plane examined. This was also done on segment 5 face 2 using 7 planes up to a depth of 0.0084 inches $(.021 \mathrm{~cm})$; each plane examined in this instance represented only a small change in the depth below the previous surface examined.

The results of the observations made on these two segments follow: Only a tac weld was observed and no lapweld region was present; voids were present predominantly in the weld metal of the tac weld; the fusion boundary always contained a string of inclusions, but a continuous path was not traced through the successive sections examined.

Segment 5, face 2 had been examined on successive surfaces and after face 1 was also examined, this segment was separated into two pieces--a thicker head piece with some weld metal attached and a thinner shell piece with some weld metal attached. The separation was accomplished by first separating the two pieces with a small saw cut in the segment at the end that did not contain the weld metal, then prying open this saw-cut slit with a chisel, and then pulling the two pieces in tension until the weld metal was completely fractured. In this way, it was possible to later examine the fracture face and to observe the path along which the two pieces fractured. It was believed, that a segment fractured in this manner would give evidence of pre-existing voids in the weld metal.

Segment 5 in the partially fractured condition is shown in Figure 10, in which the piece of the head is shown on the right and the shell on the left. The arrow in between the head and shell pieces points to a dark region along the bond line. This dark region is a void region in the partially fractured surface of weld metal, and it is believed to have existed prior to this separation. After the pieces were completely separated, the appearance of the fracture in the region just below this dark region was dull in comparison to that of the adjacent regions on the balance of the fracture faces. The balance of the fracture was bright and crystalline in appearance. The fracture face of the piece of the shell was observed in detail using the scanning electron microscope. The head piece of this fracture was used for metallographic studies.

In the metallographic studies, the head piece with its weld metal was polished and etched on successive weld-metal 
layers beneath the level of the fracture face of the weld metal. In several of these layers there existed weld-metal with gross porosity and oxidation which extended from outside of the tank on the face of the weld to within the tac weld metal. After successive weld-metal layers were removed microporosity only was present. Figure llA shows the region of porosity at one level at which it extended to the outside of the tank and Figure IIB shows the region at another level at which it was essentially contained within the weld metal. Surrounding the pores there is evidence of corrosion. While this corrosion could have been the result of some externally prompted corrosive action, we suspect that it may be a result of internally prompted corrosion, and that it may be the actual site of the leak. However, the micropores observed at the internal weld metal site were not successfully traced all the way to the root of the tac weld inside the vessel.

\subsection{Scanning-Electron-Microscope Examinations}

Several scanning-electron-microscope (SEM) fractographs were taken of the fracture faces of the shell portion of the separated segment number 5. These fractographs showed that the fracture was crystalline in appearance except for the region beneath the dark spot shown in the photograph of Figure 10. The non-crystalline appearance of the metal beneath this dark spot was observed to be present along a continuous path from the inside to the outside of the tank on this fracture face.

Figure 12 shows the fracture face on the shell portion of segment 5 at a magnification of $\times 5$. The arrow on the figure points in the direction of crack propagation (during separation from the inside to the outside of the tank) and it is located at the dark part shown at the arrow on Figure 7. At higher magnifications, Figure 13 shows that this dull region is non-crystalline whereas other parts of the fracture are crystallographic. Microporosity is much more prevalent in the dull region. This microporosity and the dimpled appearance of the dull region is shown at $\mathrm{X} 1300$ in Figure 14A, and the crystalline appearance of the balance of the fracture is represented at $\mathrm{X} 1300$ in Figure $14 \mathrm{~B}$.

It is believed that the dull region failed in a more ductile manner than did the balance of the fracture because constraint was locally decreased in this region due to the presence of the micropores that existed before the two pieces were separated to form the fracture faces. This microporosity 
was probably present in the original tac weld, just after the weldment had been deposited. In service, it is believed that corrosion acted on this region of porosity eventually to form a continuous path from the interior to the exterior of the tank.

5. Summary on the Nature and Cause of the Leak

No gross defects through which phosgene gas could have leaked from the vessel were observed and it is believed that the leak occurred through a micropath, which probably existed either along the fusion boundary of, or within, the weld metal of the tac weld present in the region of the leak. The forged weld observed at sites remote from the leak was not present at the site of the leak, and so the distance through which the micropath had to form was relatively short in comparison with that at other locations remote from the leak. It is believed that this micropath was formed by corrosion which was itself promoted by capillary action at this site inside the vessel. other factors which may have contributed to the leak, include the stress of the hydrotest and fatigue loads in service.

The available evidence indicates that the leak was promoted by corrosion. In numerous selected sites examined, there was little or no bond of the forged weld, and corrosion is believed to have led to this condition. In these places where the forged weld is expected to have once been, there is observed evidence of local accelerated corrosion in the form of pockets (See Figure 8). We interpret these findings as indications of corrosion along the forged weld bond line. Furthermore at the tip or end of the regions in which there was no forged weld metal, the root of the tac weld was partially separated along the fusion line and this separation is also believed to have resulted from local corrosive attack. In addition, microporosity was observed, particularly in the region of the tac-weld metal of segment 5 , and this too is believed to have resulted from corrosive attack.

The corrosion is believed to have been promoted by the geometry inside the tank at the weld joint. At this location, the tank head and sheel plates come together in a wedge shape, with the point of the wedge being at the bond line between the plates. Thus, a very narrow gap existed inside the tank at the forged weld bond. We believe that this narrow gap promotes capillary action and the retention of liquids. Furthermore, we can conceive of local corrosive attack or 
crevice corrosion ${ }^{3}$ ) due to this capillary attraction. For example, water that is retained in this capillary would react with phosgene and form 4 ) hydrochloric acid (HCI) in the capillary, with a resultant expectation of local corrosive attack along the bond line.

The failure of this tank occurred during the first "out of plant" service after a hydrotest of this vessel; it can be argued that the stress of the hydrotest and the subsequent corrosive attack (by the above mechanism) may have accelerated the final linking of microvoids and voids, and that the hydrotest thereby accelerated the formation of the leak observed in service. It can also be speculated that in service, these vessels can receive fatigue loads of sufficient magnitude to promote the linking of voids over short distances within the bonded region between the head and shell plates. However, no direct evidence of fatigue markings were observed in our investigation.

\section{ACKNOWLEDGEMENTS}

The extensive metallographic studies of this project were conducted by C. H. Brady, and by G. E. Hicho and D. E. Harne who also supervised the weighing of the tank and assisted $T$. R. Shives in conducting the magnetic-particle and dye-penetrant tests. T. P. Royston supervised the flamecutting and sectioning operations and he provided the photographic documentation of the tank after sectioning. Helpful suggestions were made to the author by Drs. M. L. Picklesimer, J. H. Smith, and J. R. Ambrose.

\section{REFERENCES}

1. McCaffery, E., J. Electronchem Soc., 1974, 121, p. 1007.

2. Rosenfeld, I. I. and Marshakov, I. K., Corrosion, 1964, $20, p .115 t$.

3. Evans, Vlick R., The Corrosion and Oxidation of Metals: Scientific Principles and Practical Applications, Edward Arnold (Publishers) Ltd., 1960, p. 528, 529.

4. Wertheim, E., Textbook of Organic Chemistry, Second Edition, The Blakiston Company, Philadelphia, 1945, p. 260 . 


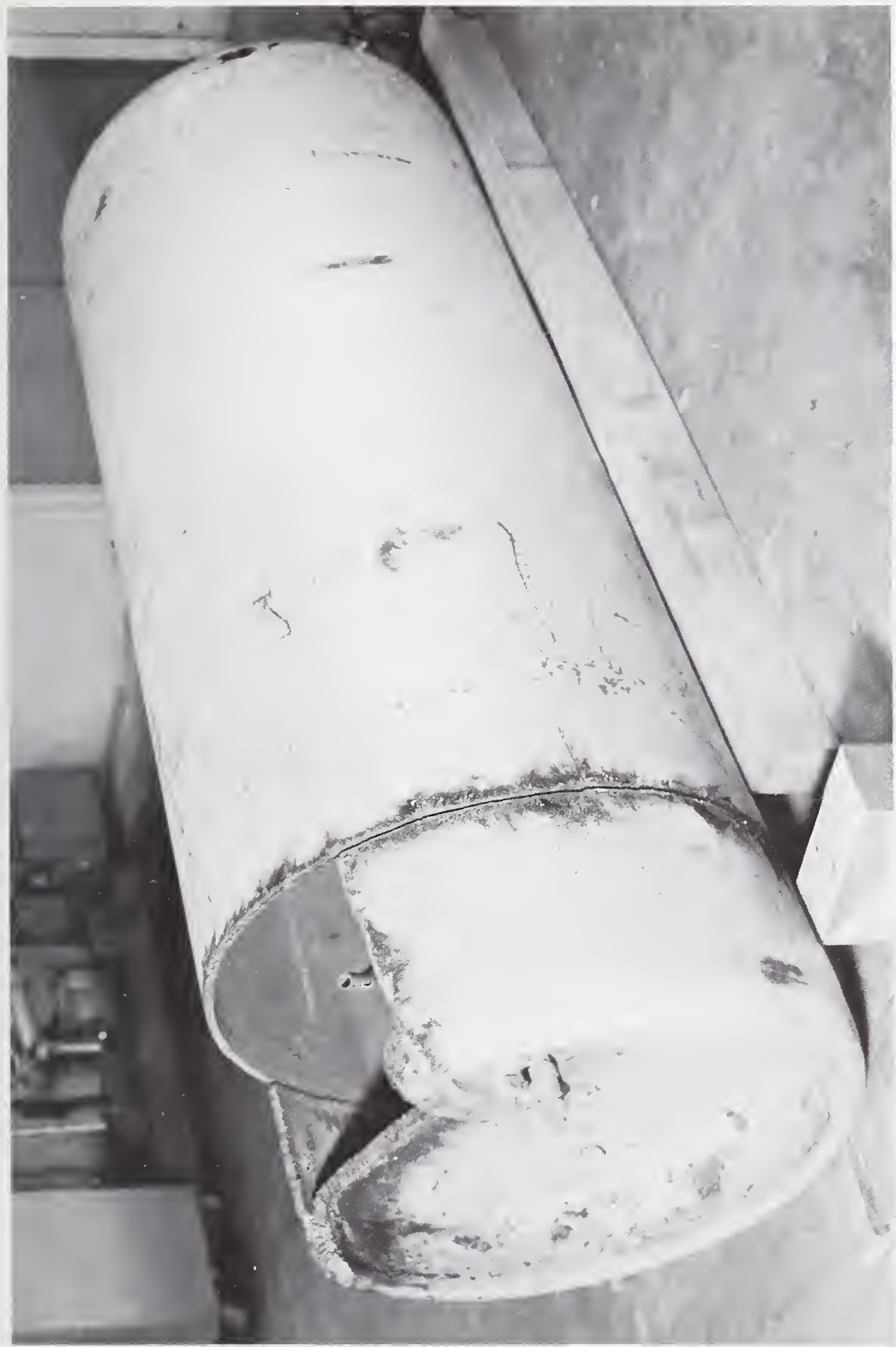

$\frac{1}{4}$

莫

व्व

(1)

(1)

30

ह

다

0

or

c.

- -1 ช

$++$

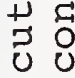

$\notin+$

藏

단

(4)

(1) -

40

त 0

岂俈

(1) 总

$-1$

4
4
3
0
-15
[1 



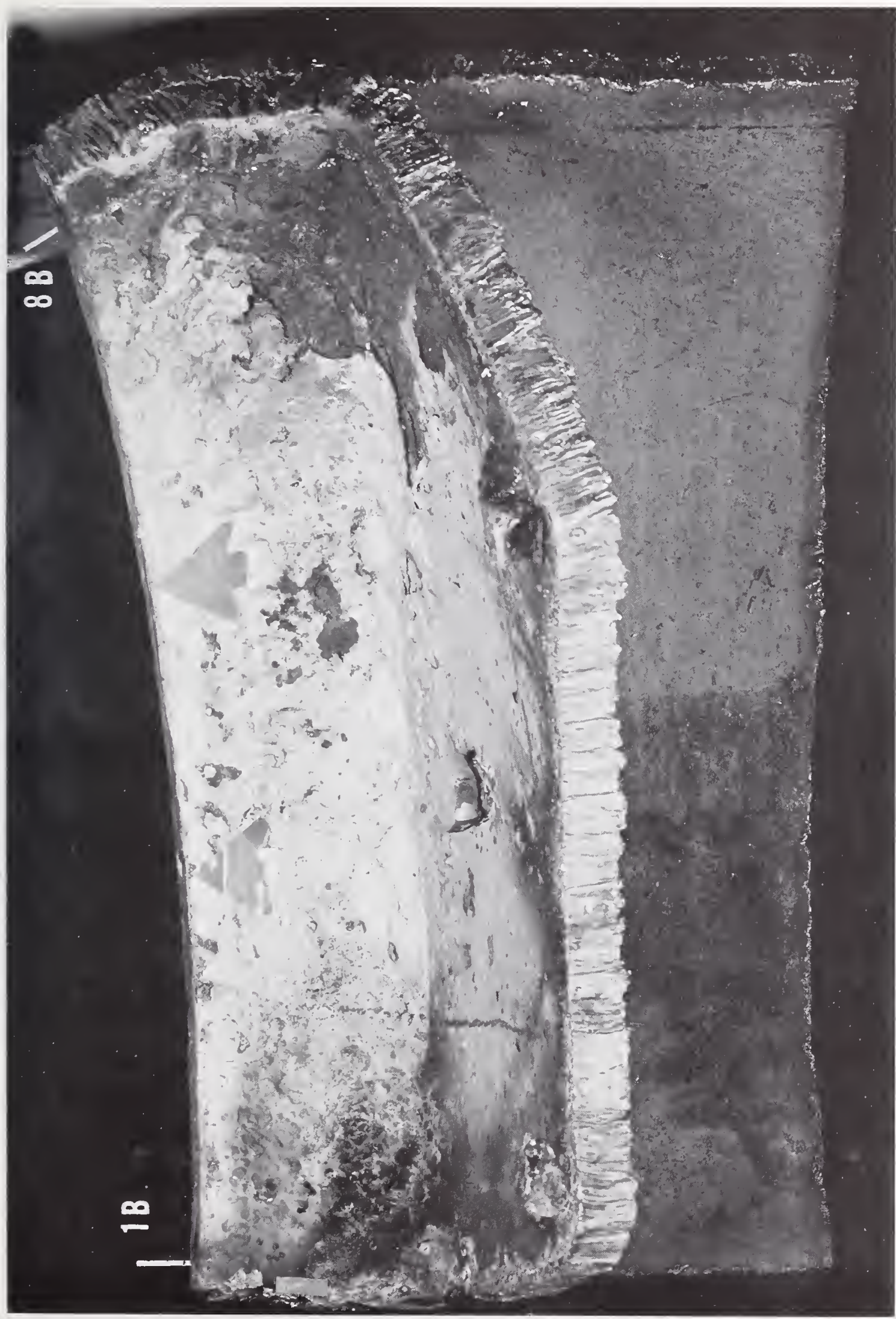

통

$4-1$

+

$3+$

10

E

$\sigma$

더넌

थ

ए

i)

隶

(1) प

-1

(1)

过

0

ช 4

Q

.

ก 0 U

$+03$

द.

ठ大

更

\% 0

近艺䓵

E

ह

$+y^{4}$

Ч द

ज䒠

(1) 0

قِّ لِّ

$\dot{v}$

岂 



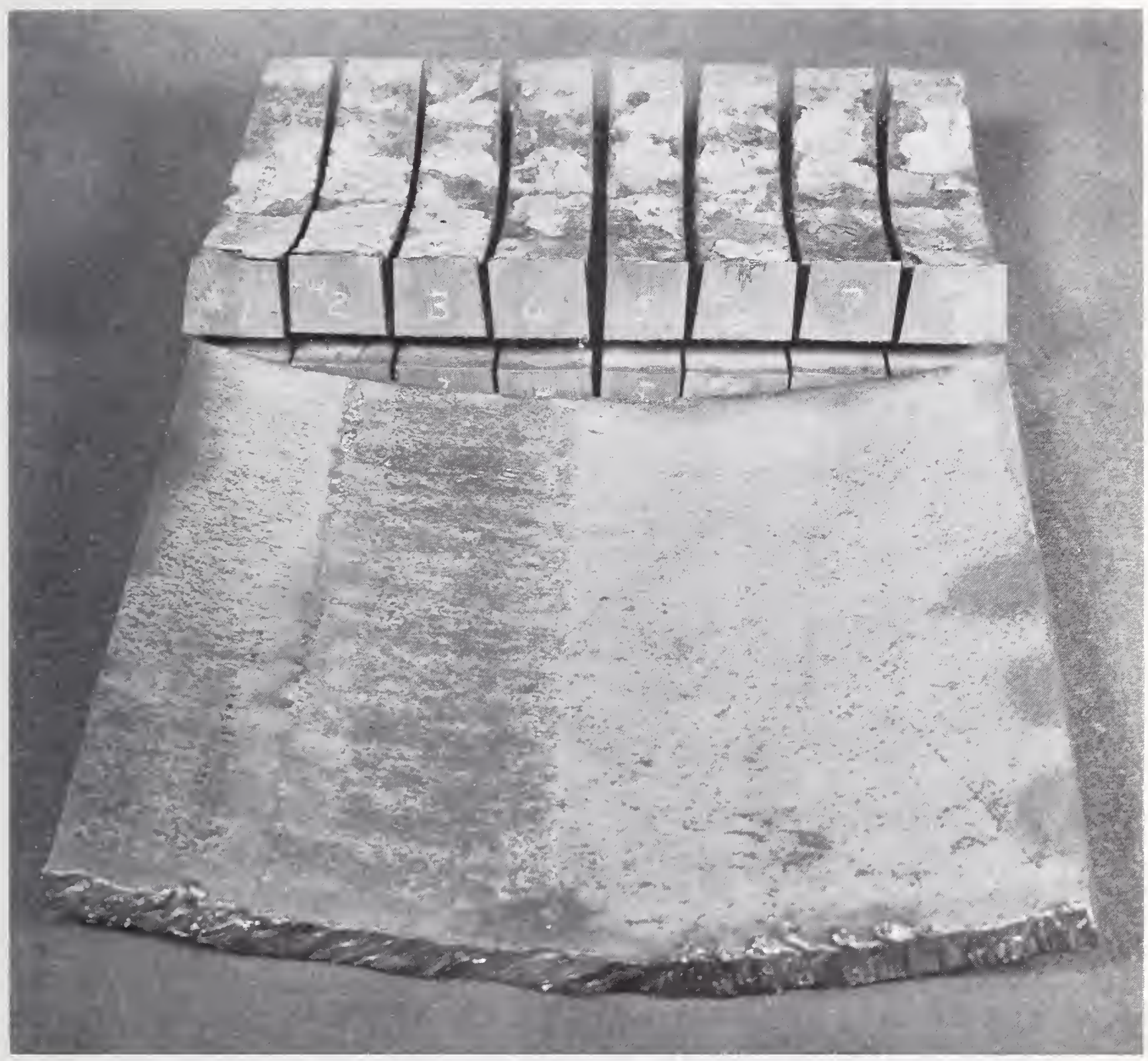

Figure 3. Eight 1-inch segments as saw-cut from the section that contained the leak. Part of the shell plate that adjoined these segments is also shown. 



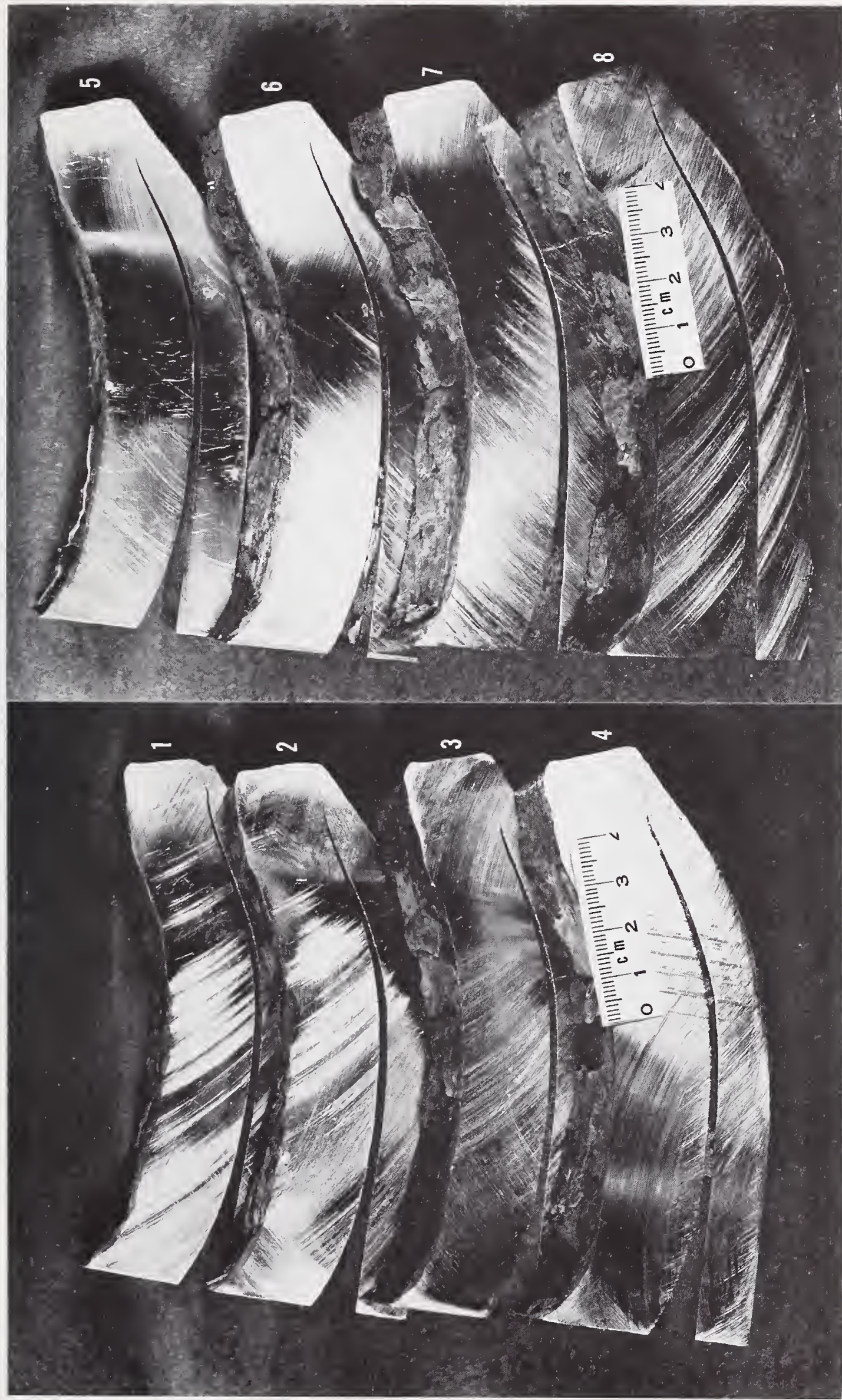






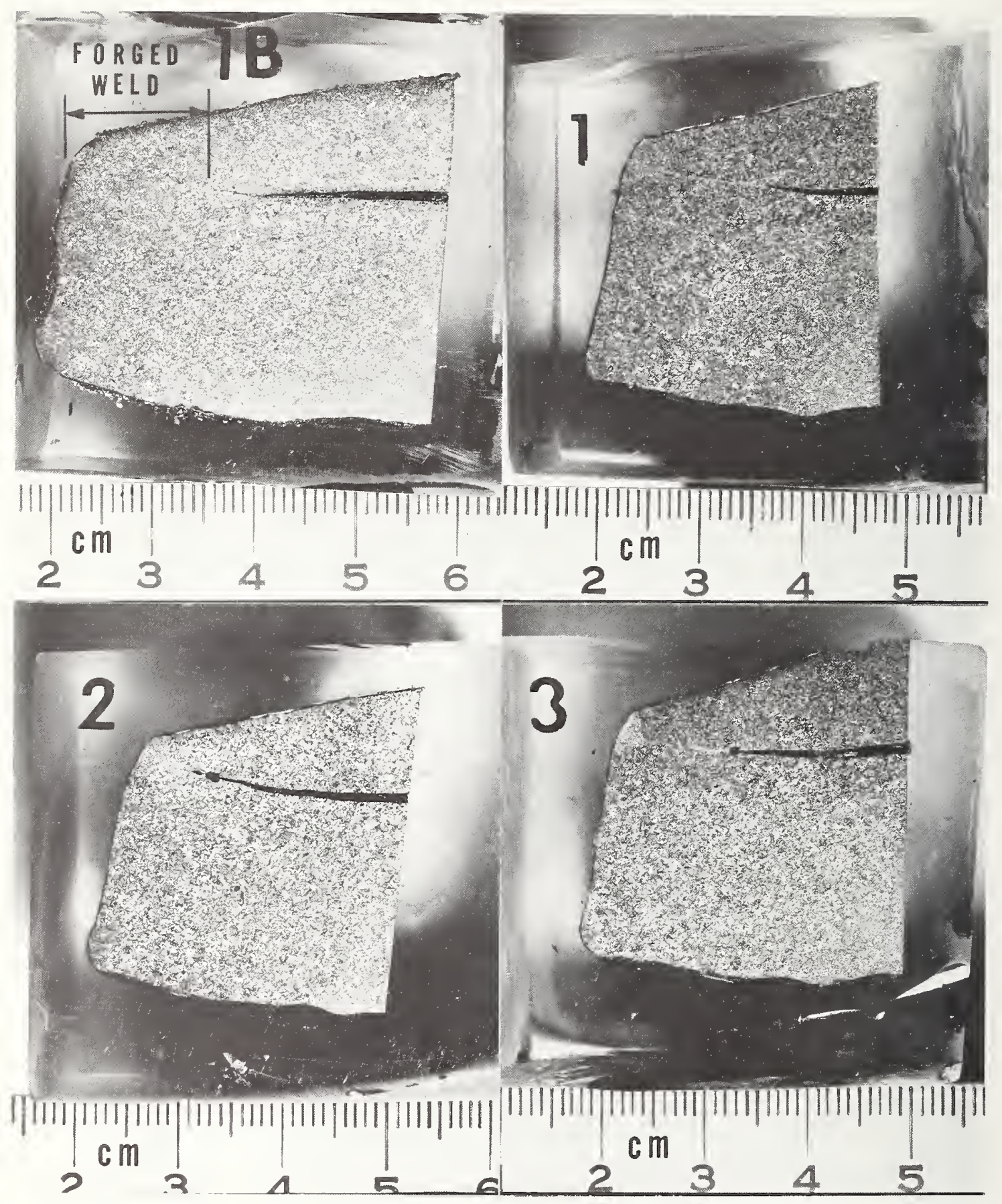

Figure 5. Eight 1-inch segments from near the leak and two end segments taken from the section that contained the leak, in the cropped, polished, and etched condition. 

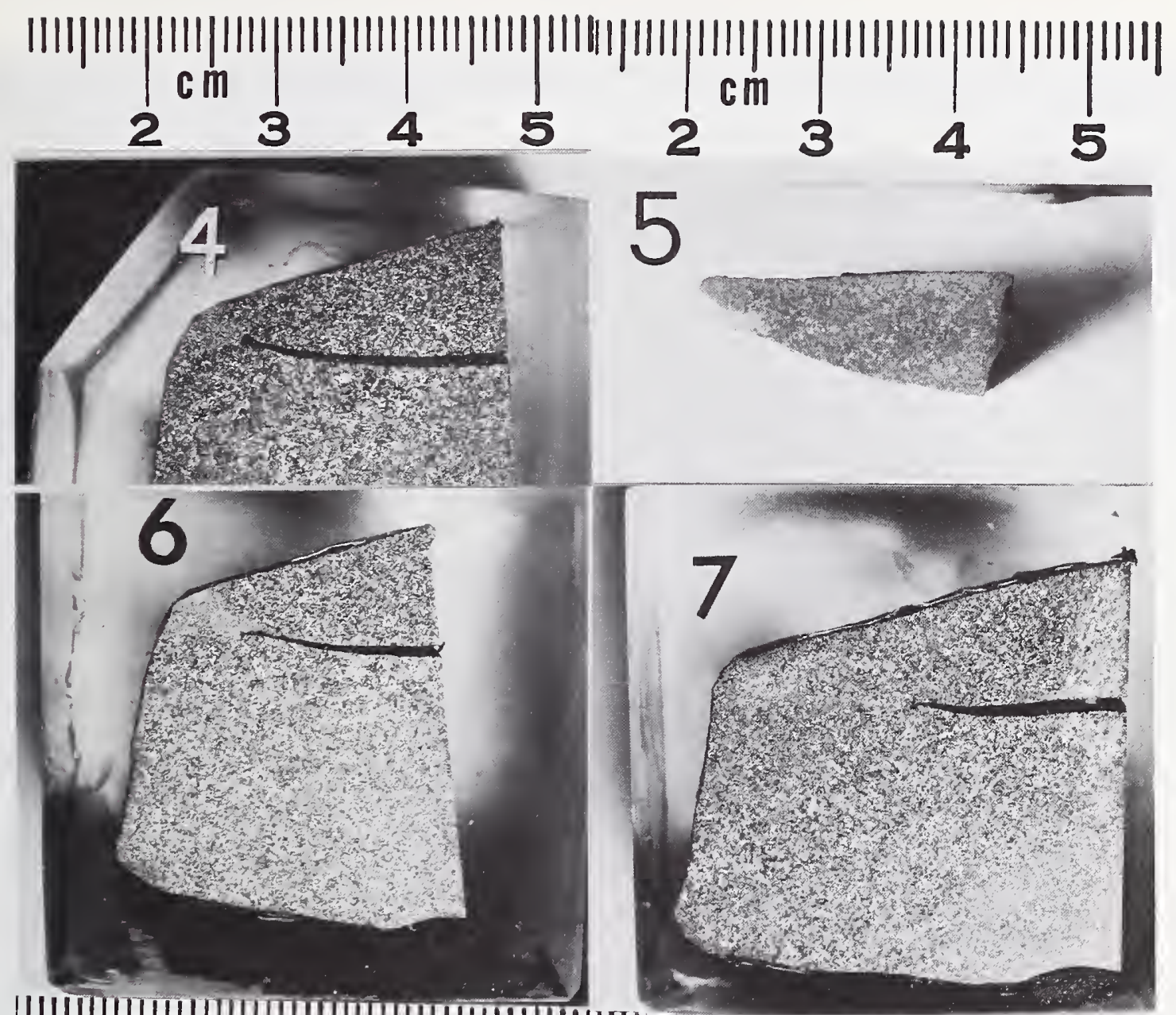

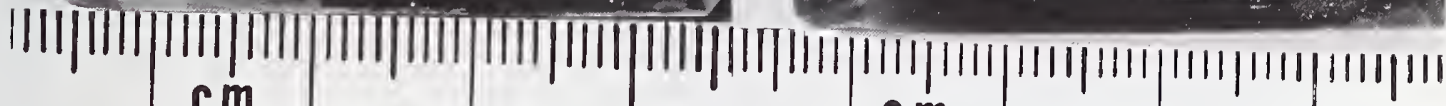
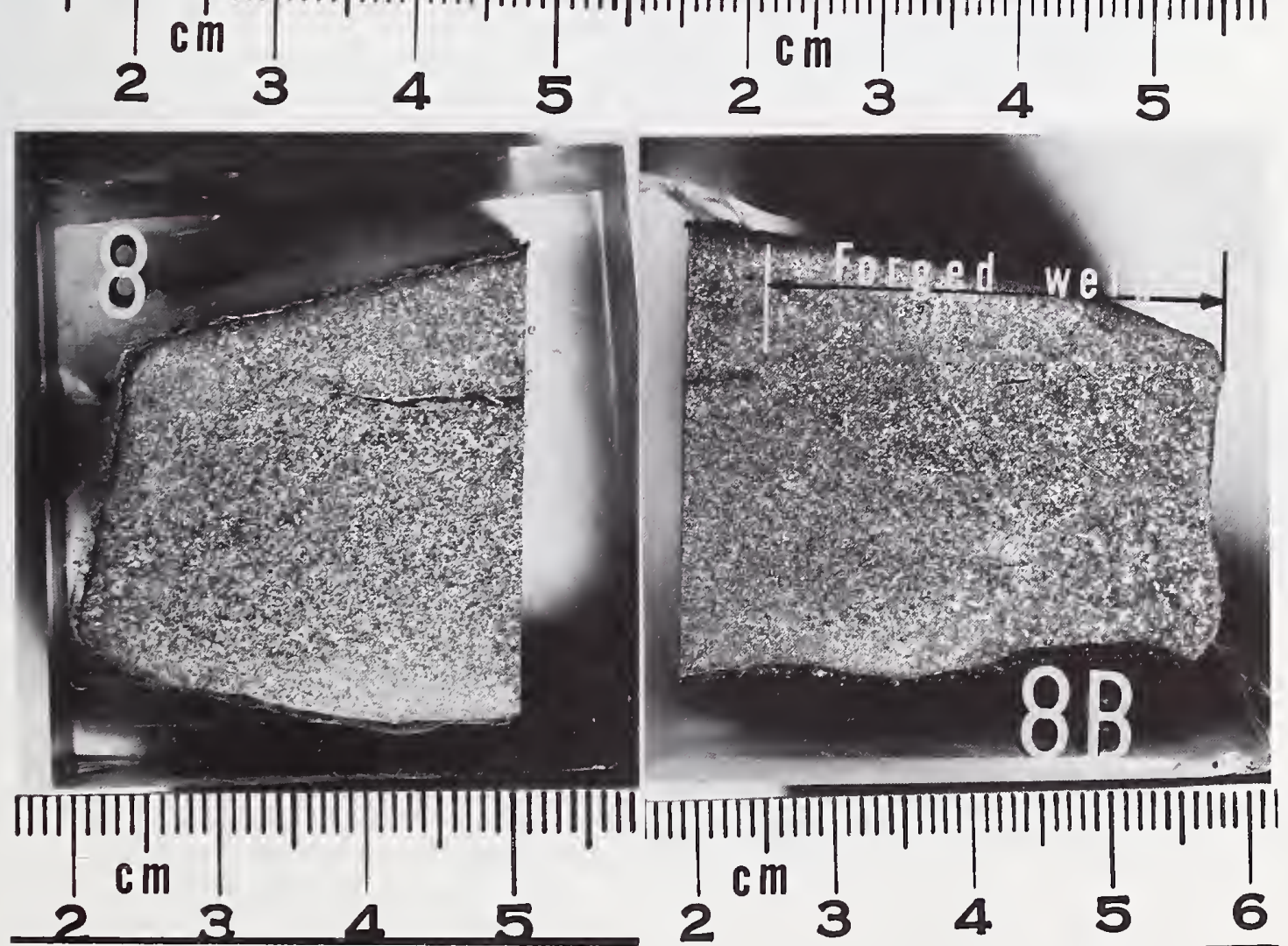



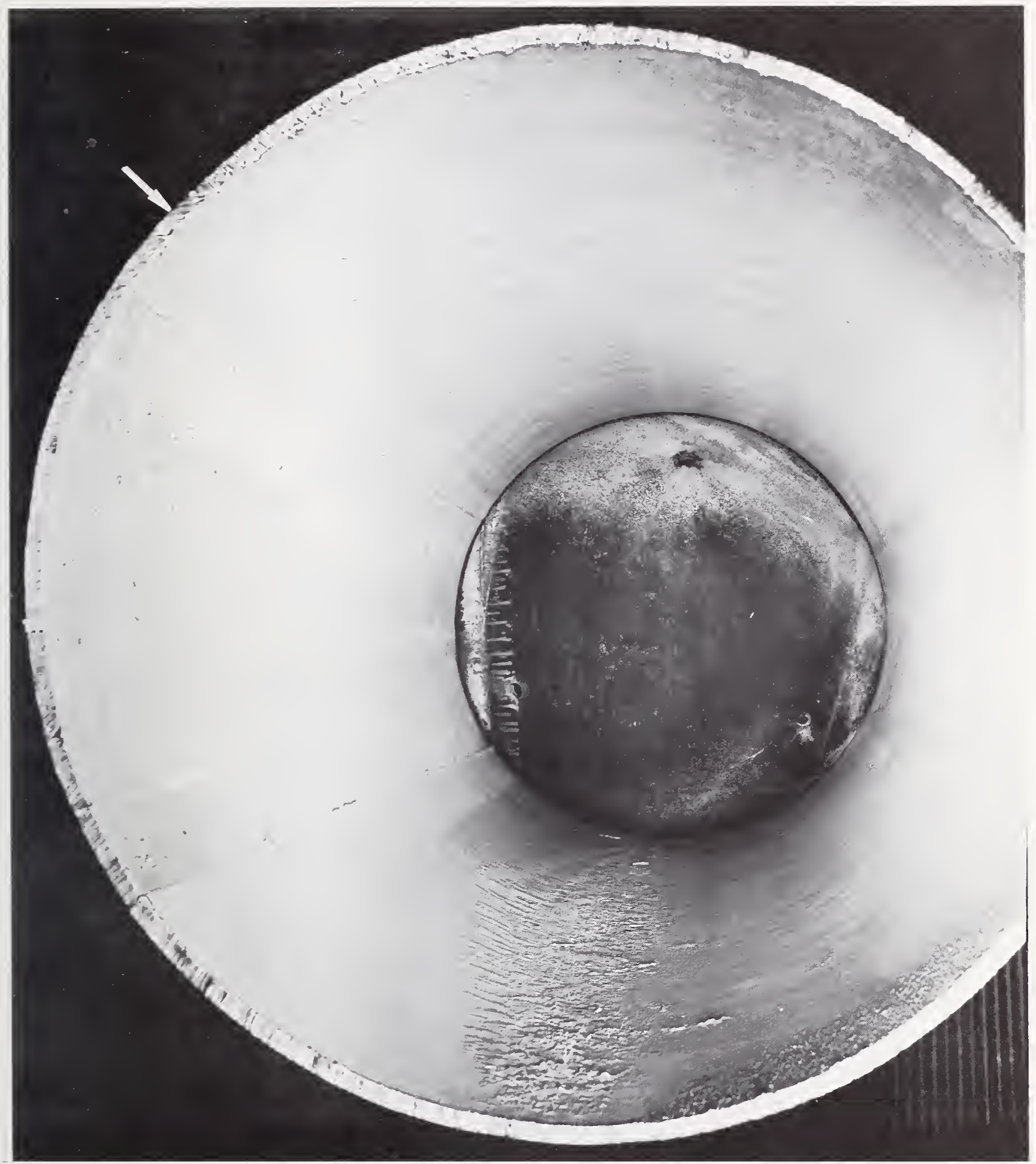

Figure 6. Inside of tank after removal of the end that leaked. The arrow marks a faint corrosion line located at saw-cut boundary of segments 4 and 5 , which were taken from the flame-cut section of the tank. This arrow is also approximately centered on 2 white marks at 9 o'clock and 12 o'clock. These marks show the limits of the flame-cut section. 



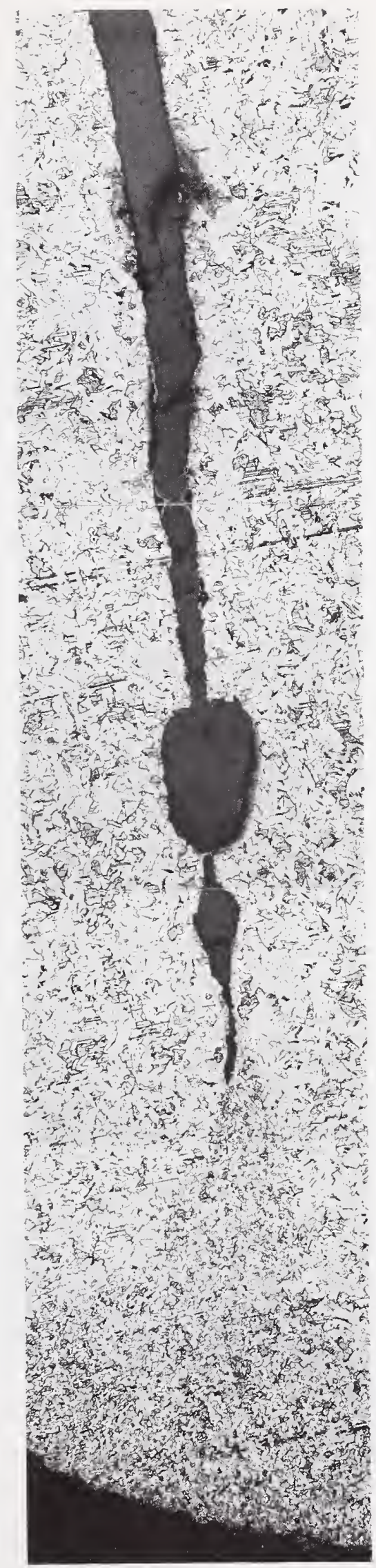

Figure 7. Montage of bond region on segment number 2 , face 1 . 

$+2$

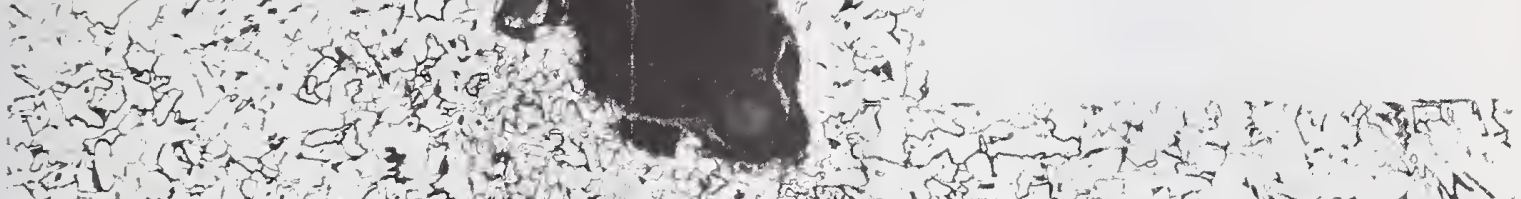

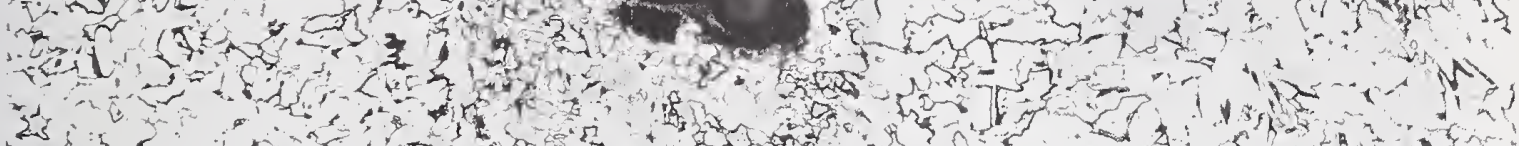

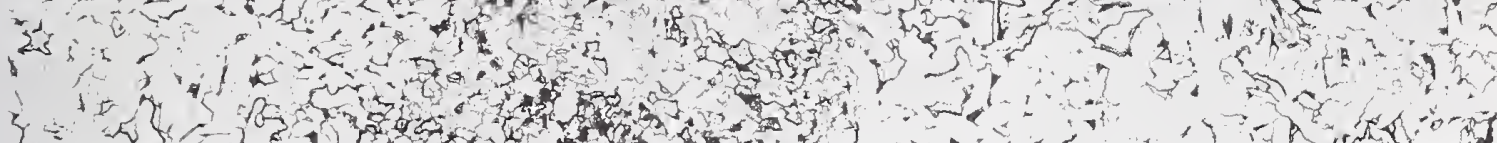

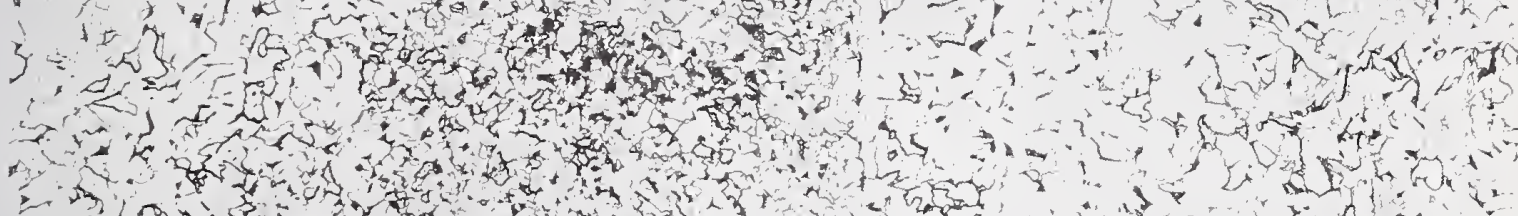

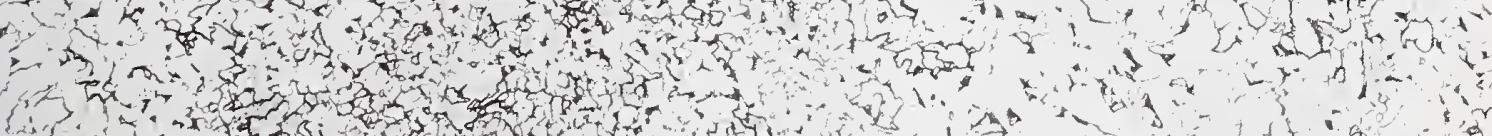

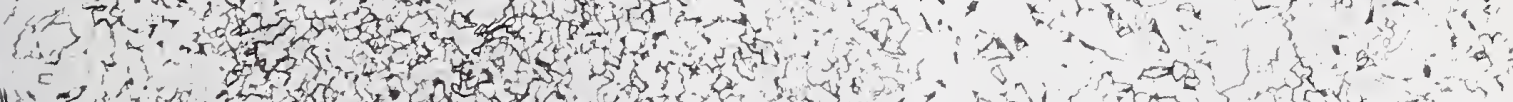

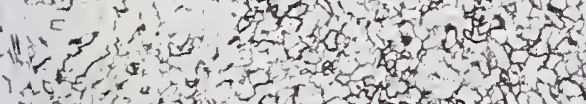

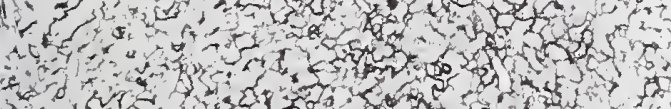

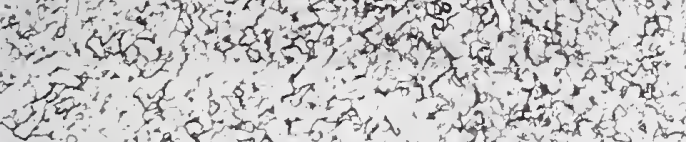

(5)

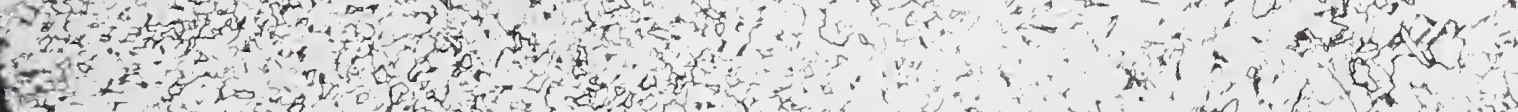

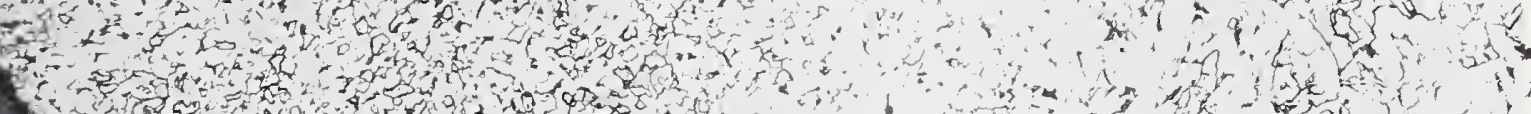

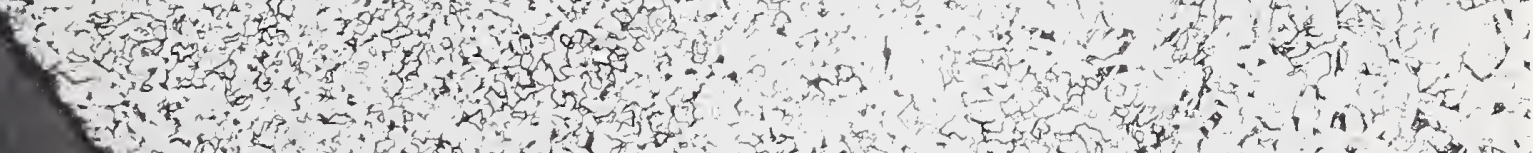

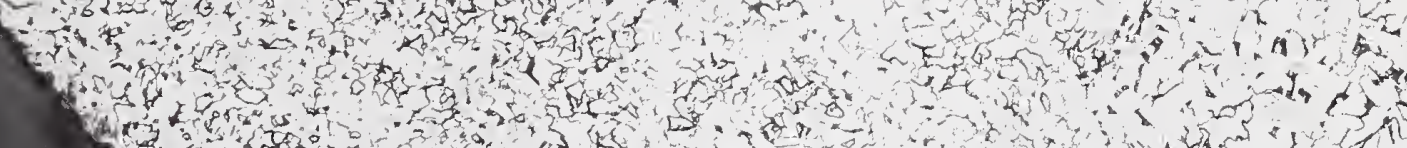

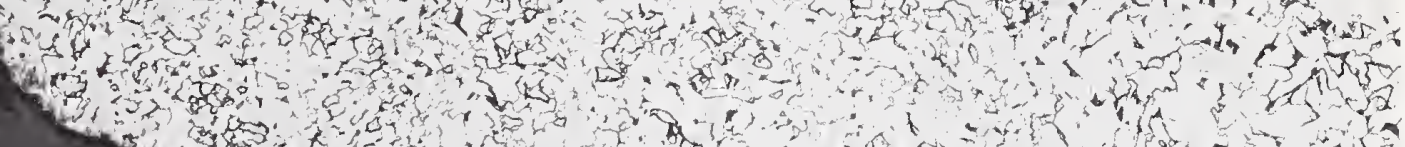
(4)

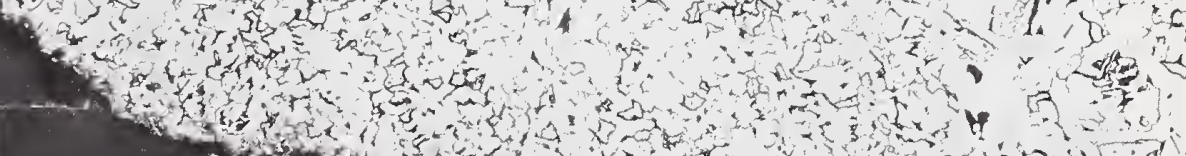

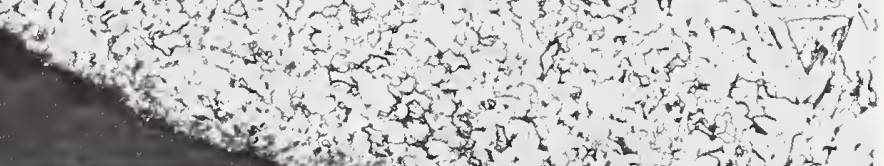

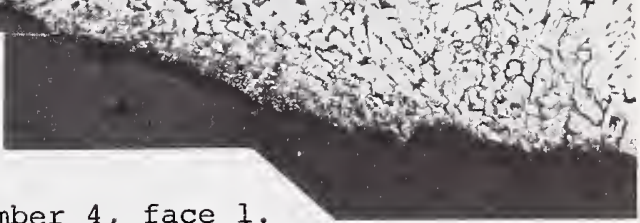

Figure 8. Montage of bond region on segment number 4 , face 1 . 



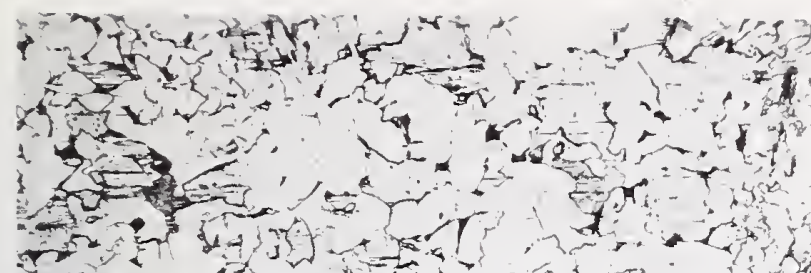

(a) 6.

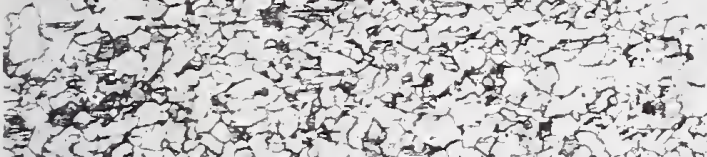
3, (3)

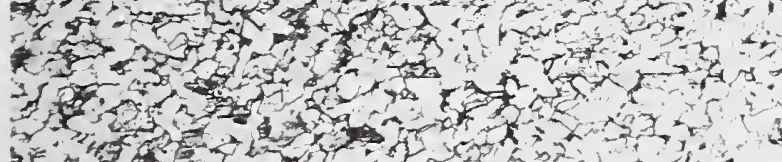
3f की

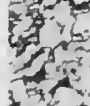

sicis

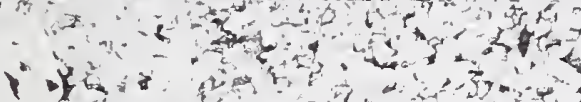
20.5 



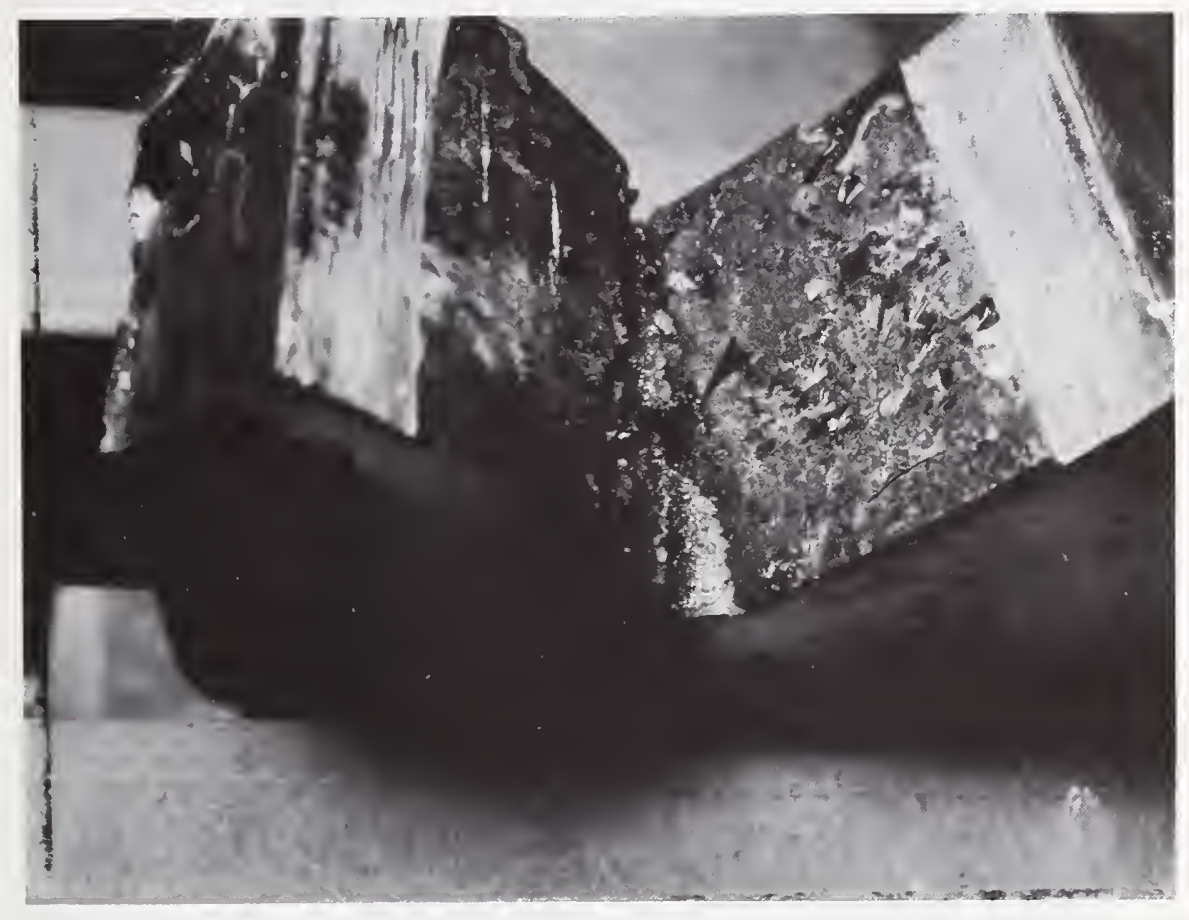

Figure 10. Segment number 5 after being wedged open to examine for cracks, showing the location of a dark region (at the arrow) which represents a possible preexisting path through the tac weld. 



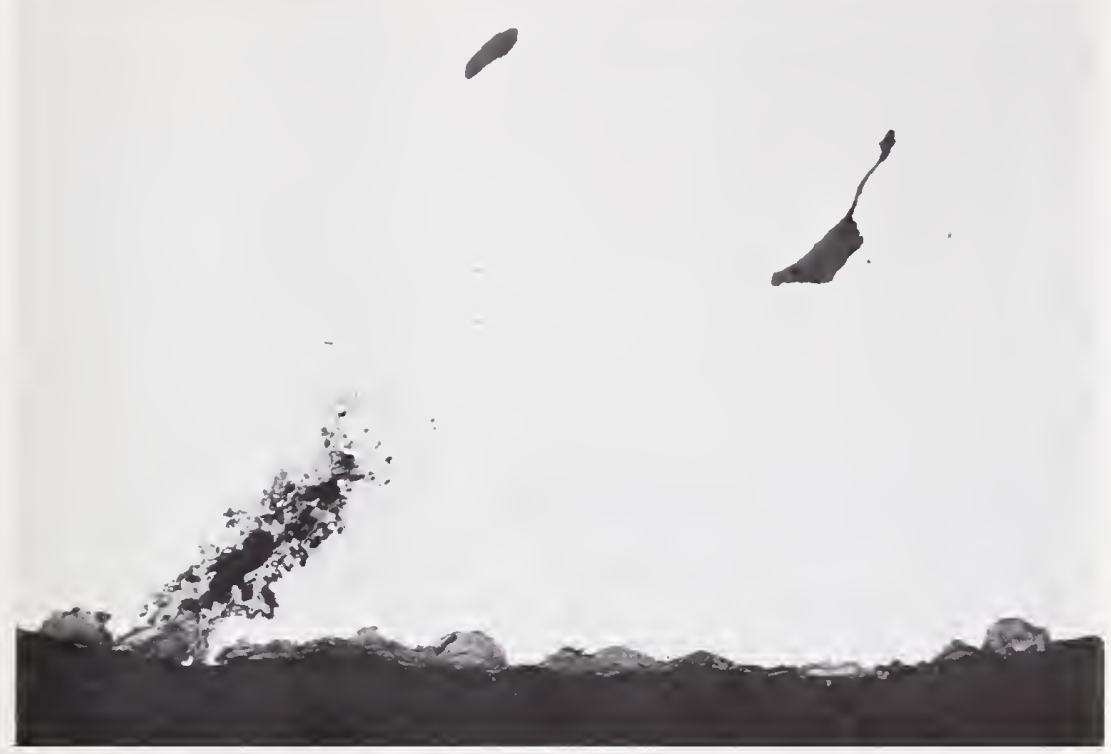

Fig. $11 \mathrm{~A}$

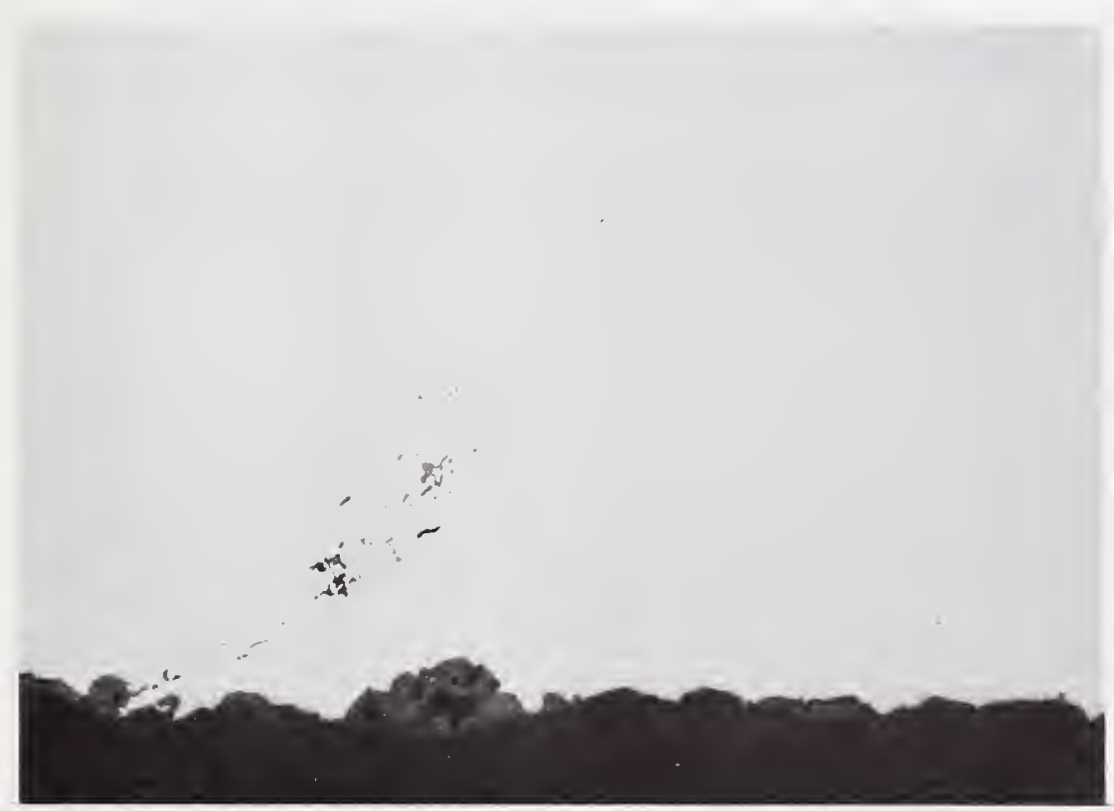

Fig. $11 B$

Figure 11. Two sections taken in the weld metal on the headplate portion of fractured segment 5 , showing surface (IIA) and sub-surface (IIB) defects and oxides that surround them. 



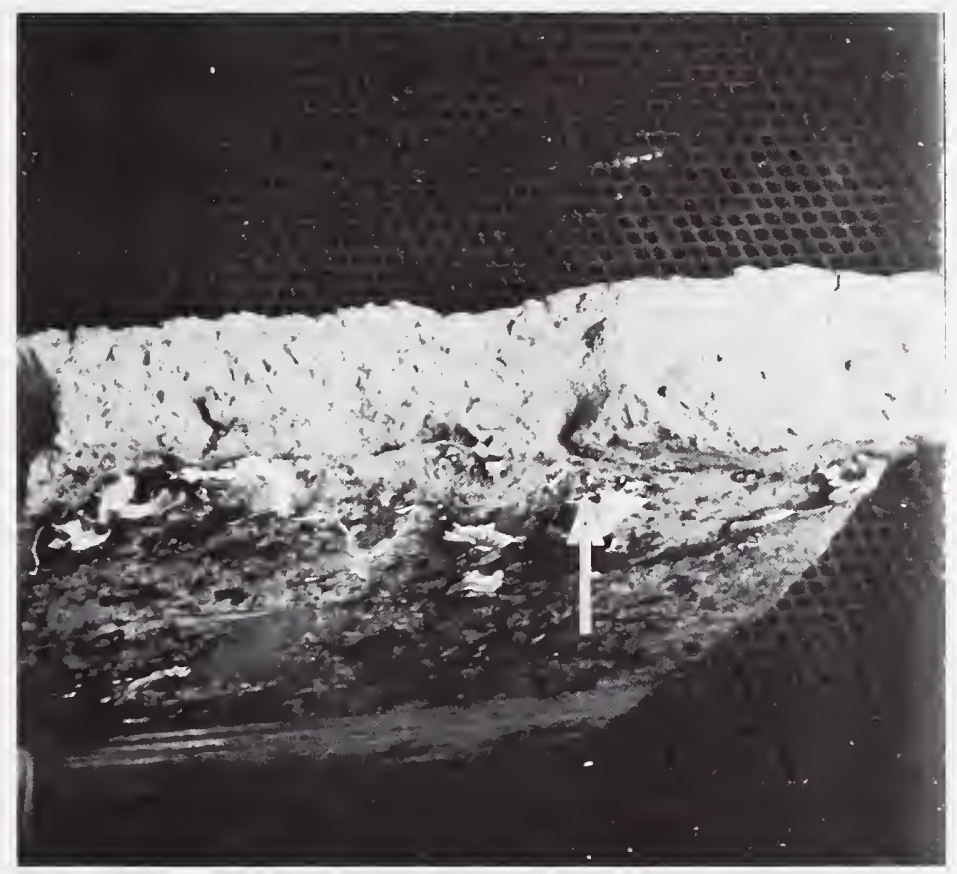

Figure 12. SEM fractograph of fracture face of segment 5 taken at $\mathrm{X} 5$ magnification. The arrow points in the direction of crack propagation and it is located at the "dark part." 



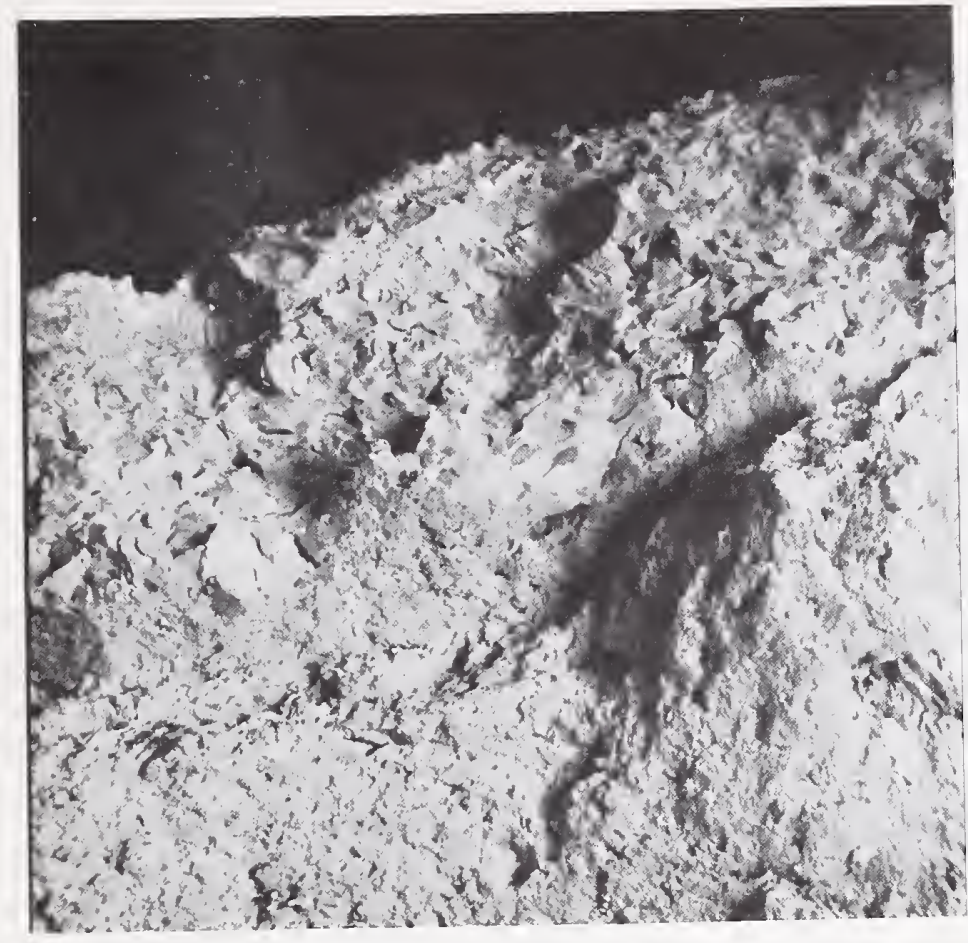

Fig. 13A

$\mathrm{X} 48$

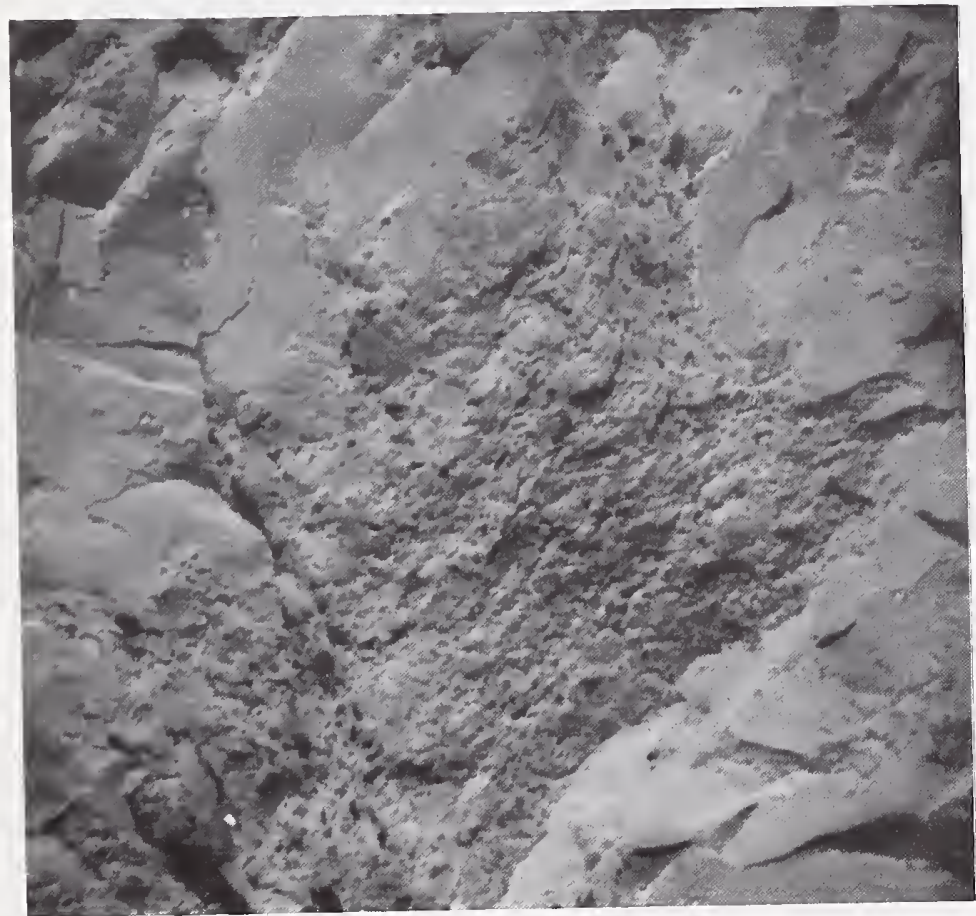

Fig. 13B

$\mathrm{X} 240$

Figure 13. SEM fractographs taken at X48 (Fig. I3A.) and X240 (Fig. 14B.) showing microporosity in the dull region and crystalline fracture in the adjacent parts of the fracture. 



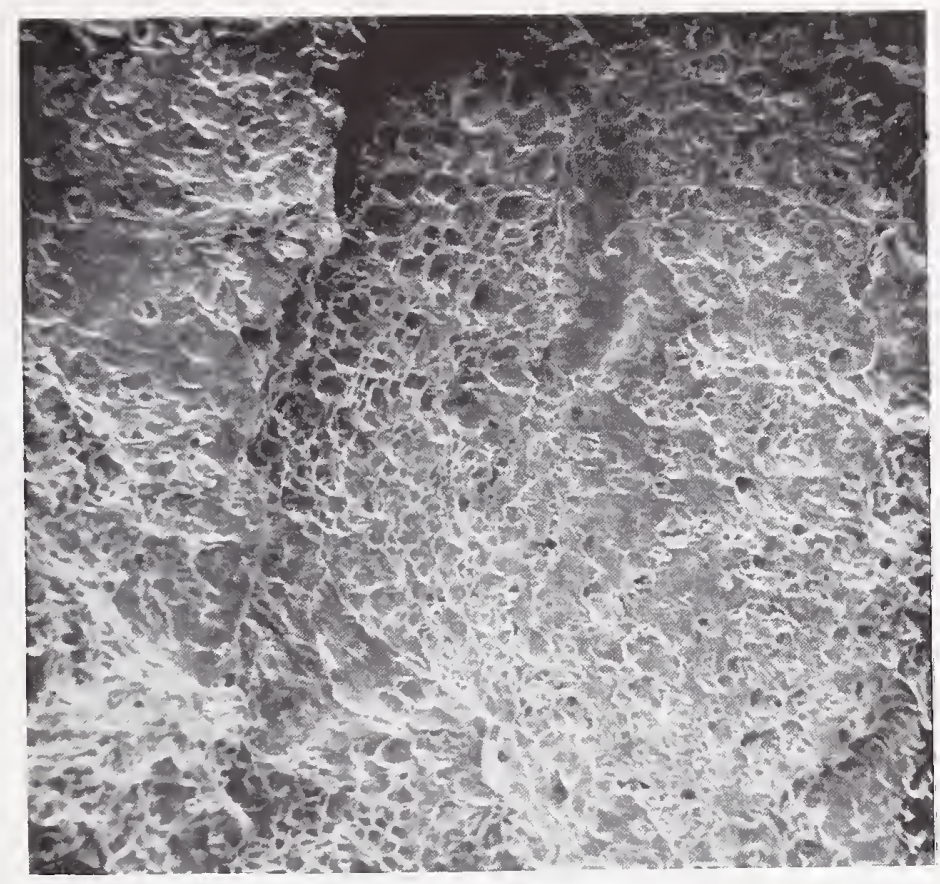

Fig. $14 \mathrm{~A}$

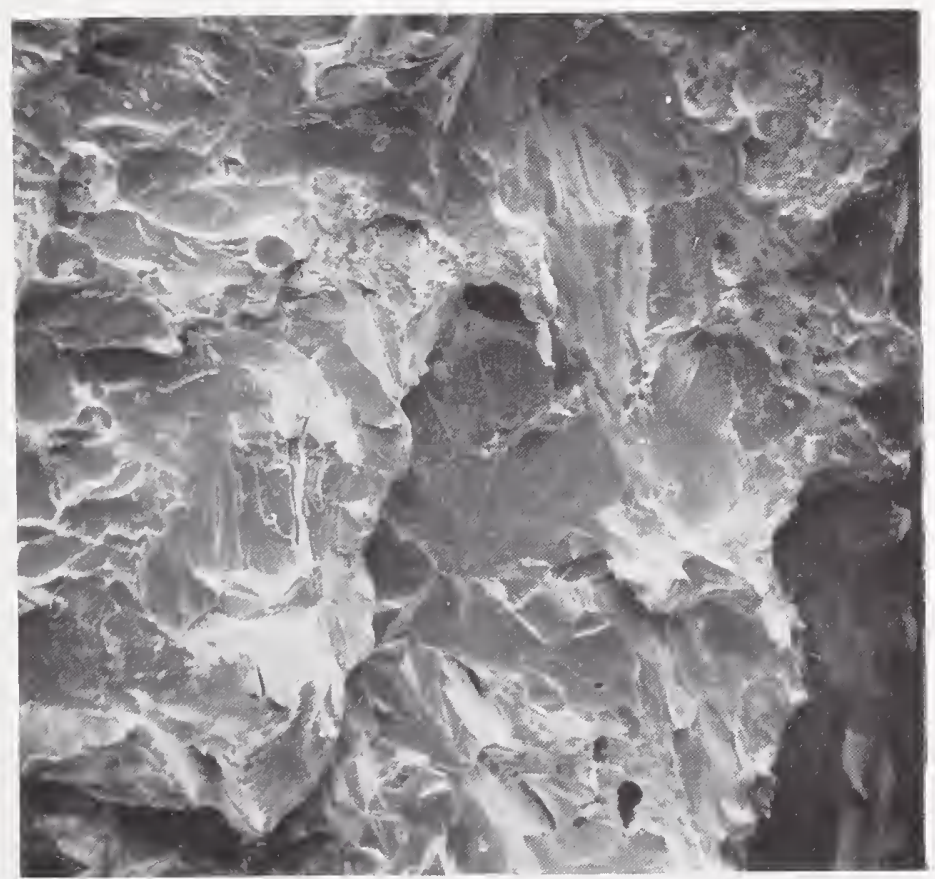

Fig. 14B

Figure 14. SEM fractographs of the dull region (Figure 14A), showing microporosity and dimpled rupture, and of a region representative of the balance of the fracture (Figure 14B), showing a crystalline appearance. 

NBS. 114A IREV. 7.73 )

\begin{tabular}{|c|c|c|}
\hline $\begin{array}{l}\text { U.S. DEPT. OF COMM. } \\
\text { BIBLIOGRAPHIC DATA } \\
\text { SHEET }\end{array}$ & \begin{tabular}{l|l} 
1. PUIH.IC ATION OR RH.PORT NO. & 2. Gov't Accession \\
NBSIR 75-704 & No.
\end{tabular} & 3. Recipient's Accession No. \\
\hline \multirow{2}{*}{\multicolumn{2}{|c|}{$\begin{array}{l}\text { 4. TITI. ANI) SIBTITI: } \\
\text { INVESTIGATION OF A I-TON TANK-CAR TANK THAT LEARED } \\
\text { PHOSGENE IN EASTON, PENNSYLVANIA ON APRII 24, } 1973\end{array}$}} & $\begin{array}{l}\text { 5. Publication Date } \\
\text { April } 1975\end{array}$ \\
\hline & & 6. Performing Organization Code \\
\hline \multirow{3}{*}{\multicolumn{2}{|c|}{$\begin{array}{l}\text { 7. AUTHOR(S) } \\
\text { C. G. Interrante } \\
\text { 9. PERRORMINC, ORTIANIZATION NAME AND ADDRESS } \\
\text { NATIONAL BUREAU OF STANDAROS } \\
\text { DEPARTMENT OF COMMERCE } \\
\text { WASHINGTON, D.C. } 20234\end{array}$}} & $\begin{array}{l}\text { 8. Performing Organ. Report No. } \\
\text { NBSIR } 75-704\end{array}$ \\
\hline & & $\begin{array}{l}\text { 10. Project/Task/Work Unıt No. } \\
3120110\end{array}$ \\
\hline & & 11. Contract/Grane No. \\
\hline \multirow{2}{*}{\multicolumn{2}{|c|}{$\begin{array}{l}\text { 12. Sponsoring Orginization Name and Complete Addres, (Streel, Cily, State, ZlP) } \\
\text { Federal Railroad Administration } \\
\text { Department of Transportation } \\
\text { Washington, D.C. } 20590\end{array}$}} & $\begin{array}{l}\text { 13. Type of Report \& Period } \\
\text { Covered Failure } \\
\text { Analysis Report }\end{array}$ \\
\hline & & 14. Sponsoring Agency Code \\
\hline
\end{tabular}

15. SUPPI.FMENTARY NOTES

16. ABSTRACT (A 200-word or less factual summary of most significant information. If document includes a significant bibliography or lileralure survey, mention il here.)

At the request of the Standards and Procedures Division, Federal Railroad Administration, Department of Transportation, an investigation was conducted at the National Bureau of standards (NBS) on a 1-ton tankcar tank, which reportedly failed in service by leaking phosgene gas in Easton, Pennsylvania. The tank was shipped to NBS where it was sectioned and examined to determine the nature and possible cause of the leak.

No gross defects, through which phosgene gas could have leaked, wer observed and it is believed that the leak occurred through a path of very small size, which probably existed either along the fusion boundary of or within the weld metal of a tac weld present in the region of the leak. The forged weld present at locations remote from the leak did not exist in the region of the leak and the available evidence indicates that this unbonded metal is the result of corrosion promoted by capillary action at the root of this weldment. It is believed that the observed leak was principally the result of corrosion from the inside of the vessel, and it is speculated that the failure of the vessel may have been accelerated by hydrotesting of the vessel and/ or by service-related fatigue loads on the weld joint.

17. KEY WORDS (six to twelve entries; alphabetical order; capitalize only the first letter of the tirst key word unless a proper name; separated by semicolons)

Corrosion; crevice corrosion; failure analysis; failure by leaking; fractography; hydrotest effects; mild steel; l-ton tank; phosgene container; pressure vessel

18. AVAILABILITY Unlimited

XXFor Official Distriburion. Do Not Release to NTIS

Order From Sup. of Doc., U.S. Government Printung Office

W'ashington, I).C. 20.402, S1) Car. No. C 13

\begin{tabular}{|l|c|}
\hline $\begin{array}{l}\text { 19. SECURITY CLASS } \\
\text { (THIS REPURT) }\end{array}$ & 21. NO. OF PAGES \\
UNCL ASSIFIED & 28 \\
\hline $\begin{array}{l}\text { 20. SE(URITY CLASS } \\
\text { (THIS PAGE) } \\
\text { UNCLASSIFIED }\end{array}$ & 22. Price \\
\hline
\end{tabular}

Order lirom Narional Technical Information Service (NTIS) Springfield, Virginia 22151 



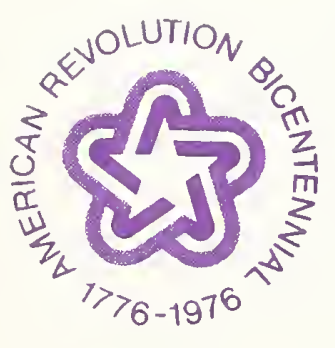

